\title{
Protective Effects of Aqueous Extract of Cinnamon on Diabetes-Induced Nephrotoxicity in Wistar Rats
}

\author{
*11ODIASE, DE; OM'INIABOHS, FAE \\ *Department of Anatomy, School of Basic Medical Sciences, College of Medical Sciences, University of Benin, \\ Benin City, Nigeria. \\ E-mail:Daniel.odiase@uniben.edu,_akpokpobe@icloud.com
}

\begin{abstract}
Diabetes mellitus is a chronic metabolic disorder with multi-systemic adverse effects on the body. Cinnamon is atraditional folk herbsused for treatment of diseases and was popularas an embalming agent. The present study was undertaken to evaluate the effect of crude aqueous extract of Cinnamon for its protective activities on diabetes-induced nephrotoxicity in Wistarrats. Twenty-four adult Wistar rats of both sexes were assigned to three groups containing eight rats $(n=8)$. Group A was the control group, group B was the streptozotocin-treated group, and group $\mathrm{C}$ was the streptozotocin followed by crude aqueous extract of Cinnamon treated group. Group B received $50 \mathrm{mg} / \mathrm{kg}$ of STZ by the intraperitoneal (i.p.) injection. Group C received $50 \mathrm{mg} / \mathrm{kg}$ of STZ i.p. and $300 \mathrm{mg} / \mathrm{kg} / \mathrm{day}$ of the aqueous extract of Cinnamon for 21 days. All the rats including the control group were fed with commercially formulated feeds and water ad libidum for the same number of days.Effect of concurrent oral administration of crudeaqueous extract of Cinnamon at a dose of $300 \mathrm{mg} / \mathrm{kg} / \mathrm{day}$ on the renal integrity was determined using serum creatinine, blood urea as indicators of kidney damage supporting histopathological findings. It was observed that the crude aqueous extract of Cinnamon significantly protect rat kidneys from diabetes-induced histopathological changes. This extract also normalized the increase in serumcreatinine and blood urea that characterized the diabetic group of rats.In conclusion, administration of aqueous extract of Cinnamon protects the kidneys of adult Wistar rats against diabetes-induced nephrotoxicity. (O JASEM
\end{abstract}

https://dx.doi.org/10.4314/jasem.v21i3.11

Keywords: Aqueous extract, Cinnamon, Histological, Nephrotoxicity, Streptozotocin(STZ), Integrity.

Kidneys are highly vulnerable to damage caused by reactive oxygen species (ROSs), likely due to oxidative stress by polyunsaturated fatty acids in the composition of renal lipids (Ozbek, 2012). This damage can also be caused by a high volume of blood flowing through it, and filtering large amounts of toxins, which can concentrate in kidney tubules (Begum et al., 2011). The kidney's response to toxicants varies by multiple morphological patterns beginning with tubular or interstitial changes to nephropathy (Silva, 2004). It has been strongly implicated that (NADPH) oxidase, as a major source of ROSs production in the kidney (Etoh,et al., 2013) could have a role in the development of renal oxidative damage.

Streptozotocin is a deoxy-s [(methyl-nitrosoamino carbonyl)-amino]-D glucose pyranosemolecules that produces a selective toxic effect on $B$-cells of the kidneys by generating free radicals and induces diabetes mellitus in most laboratory animals (Shradha and Sisodia, 2011). It is a monofunctionalnitrosourea derivative isolated from Streptomyces

achromogenes. It has broad spectrum antibiotic activity and antineoplastic properties and its often used to induce diabetes mellitus in experimental animals through its toxic effects on pancreatic beta cells. It is an alkylating agent known to directly methylate DNA producing DNA strand breaks (Bolzan and Bianchi, 2002).

Cinnamon was mentioned in one of the earliest books on Chinese botanical medicine (Charles, 1998). Today, it is widely used in Ayurvedic medicine (traditional Indian medicine) to treat diabetes in India (Abdul Rahim, 2009). Cinnamon cassia bark is the outer skin of an evergreen tall tree belonging to the family Lauraceae containing several active components such as essential oils (cinnamic aldehyde and cinnamyl aldehyde), tannum, mucus and carbohydrate (Ho - Keunkwen and Ji - sun Hwang et al., 2010).Cinnamom 
aldehyde (wijesekera, 1978 ), cinamamic acid (Hiromic et al., 1974), Tannun (Inokuchi et al ., 1984) and methylhydroxychal cone polymer (MHCP) (Jarvull - Taylor et al., 2001) are its main components. Cinnamon exhibits the potential to increase the amount of proteins involved in insulin signalling glucose transport and anti inflammatory / anti-angiogenesis response (Heping et al ., 2007).

\section{MATERIALS AND METHODS}

Plant Material and Preparation of Extract: The bark of Cinnamomi cassia was purchased from the vegetable market at Aideyanroad, G.R.A, Benin City, Nigeria. The plant was identified and authenticated by Sunny Nweke of the Herbarium unit, Department of Plant and Animal Biology, University of Benin, Benin City, Nigeria. The quills of Cinnamon were allowed to dry under shade and grinded into powder form in a milling machine used in grinding plant samples. $1.428 \mathrm{~kg}$ of the powdered material was packed into soxhlet apparatus and extracted using 1.6liter of distilled water. The extract obtained was concentrated using evaporation dish to yield $1.02 \mathrm{~kg}$ crude aqueous extract referred to as crude aqueous extract of cinnamon (AEC).

Experimental Animal: Adult Wistar rats of both sexes with average weight of $275 \mathrm{~g}$ were purchased, and maintained in standard animal cages from the animal house section of the Department of Anatomy, University of Benin, Benin City, Nigeria. The rats were left to acclimatize to laboratory conditions for two weeks and subsequently employed to testing for three weeks, during which they were fed with commercially formulated rat feed and water was given ad libitum. The animals were exposed to room temperature and lighting conditions, and handled according to standard protocols for the use of laboratory animals (National Institute of Health Guide for the Care and Use of Laboratory Animals (NIH, 1978).

Chemicals: Chemicals used in the current study were produced by Sigma Chemical Co. (Aldrich- Uk), ZIM Laboratory Ltd, Nagpur, India andRandox Laboratories Ltd. Admore Diamond Road, Antrim,
UK. All other chemicals and reagents used were of analytical grade.

Experimental Procedures: Twenty-four adult Wistar rats of both sexes were assigned to three groups containing eight rats $(n=8)$. Group A was the control group, group B wastreated with intraperitoneal administration of $50 \mathrm{mg} / \mathrm{kg}$ of streptozotocin while group C was further treated with $300 \mathrm{mg} / \mathrm{kg} / \mathrm{day}$ of crude aqueous extract of Cinnamon after induction of diabetes mellitus with intraperitoneal injection of $50 \mathrm{mg} / \mathrm{kg}$ of steptozotocin

On day 22, animals were sacrificed, blood and tissue samples were analysed for serum creatinine and urea..The serum was processed using commercially available kitsproduced by Randox Laboratories Ltd. Admore Diamond Road, Antrim, UK and purchased from Wosco Chemical Company, Benin City. Changes in body weights of the animals were recorded.The kidneys were prepared for histological examinations.

Assessment of Renal Function: A blood sample was withdrawn from abdominal aorta and collected into a plain tube with activated gel for determination of serum creatinine and urea levels. The samples were allowed to clot, centrifuged and sent for analysis using a standard automated technique in the Central Diagnostic Laboratory (CDL), University of Benin Teaching Hospital, according to the procedures described by the manufacturers.

Histopathological Examination: Kidneys of the animals were halved through a coronal section after removal from the body. Then the two halves were fixed by a $10 \%$ solution of formalin for several days. After processing, they were embedded in paraffin and cut into 5 micrometer sections. The sections were mounted on glass slides and stained with hematoxylin and eosin (H \& E) for light microscopic analysis.

Statistical Analysis: All data were expressed as mean \pm standard error of the mean (SEM) and statistical analysis was performed using SPSS for Windows version 17.0 (SPSS Inc. Chicago, IL, USA).

\section{RESULTS AND DISCUSSION}

Table 1: Effects of aqueous extract of Cinnamon on plasma creatinine and blood urea

$\begin{array}{lll}\text { Groups } & \text { Serum Creatinine }(\mathrm{mg} / \mathrm{ml}) & \text { Blood Urea }(\mathrm{mg} / \mathrm{ml}) \\ \text { Control } & 0.86 \pm 0.30 & 22.88 \pm 2.17 \\ \text { STZ-treated } & 2.71 \pm 0.66 & 50.50 \pm 4.51 \\ \text { STZ-treated + Cinnamon } & 0.80 \pm 0.33 & 20.00 \pm 6.88\end{array}$


Table 2: Histopathological features of the kidneys of Rats of Different treatment groups

$\begin{array}{llll}\text { Histopathological feature } & \text { Control } & \text { STZ-treated } & \text { STZ-treated +Cinnamon } \\ \text { Glomerula congestion } & -- & +++ & -- \\ \text { Blood vessels congestion } & -- & ++ & -- \\ \text { Tubular dilation } & -- & +++ & -- \\ \text { Inflammatory cells } & -- & -+ & -+ \\ \text { Reduced Glomerular space } & -- & +++ & +- \\ { }^{++} \text {Presence } & & & \\ \text { Absence } & \end{array}$

Table 3: Changes in body weight (wt.) in control, STZ-treated and STZ-treated rats with Aqueous Extract of Cinnamon

$\begin{array}{llll}\text { GROUPS } & \text { A } & \text { B } & \text { C } \\ \text { Initial body wt. }(\mathrm{g}) & 258.00 \pm 14.97 & 264.00 \pm 16.00 & 249.40 \pm 17.47 \\ \text { Final body wt. (g) } & 280.20 \pm 16.21 & 222.60 \pm 9.44 & 262.40 \pm 13.93 \\ \text { Change in body wt. (g) } & +22.20 & -41.40 & +13.00 \\ \text { Values in mean ( } \pm \text { SED) } & 267.47 \pm 6.70 & 247.33 \pm 14.49 & 256.16 \pm 3.43\end{array}$

Values are expressed mean \pm S.E.M

$* P<0.05$ as compared to diabetic induced rats

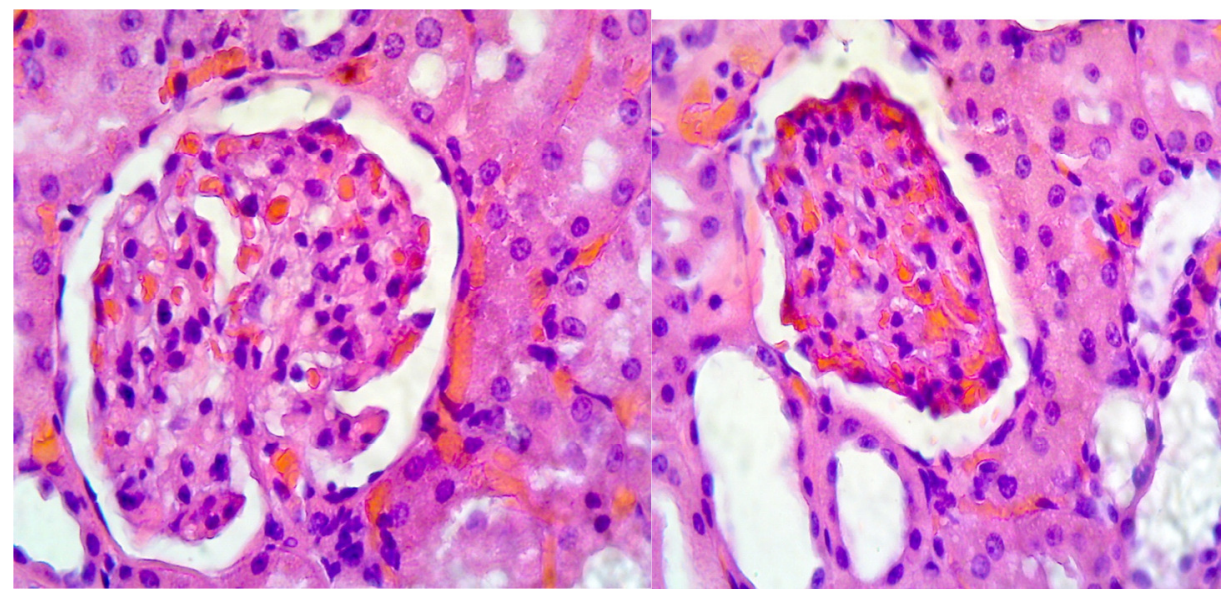

Fig. 1

Fig. 2

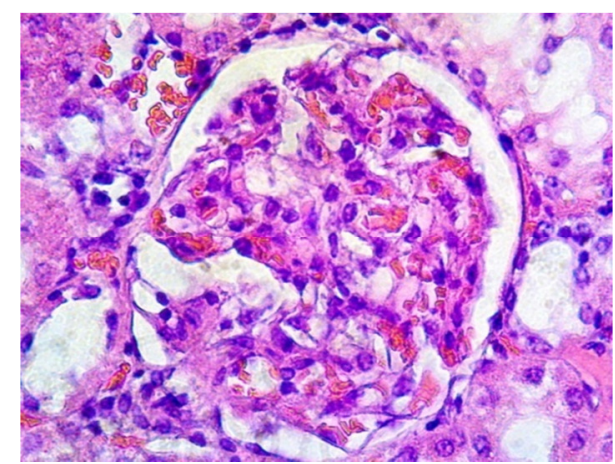

Fig. 3 
Fig. 1-3 illustrate photomicrographs (stained with Haematoxylin and Eosin, magnification 400X) to confirm the biochemical results of rat kidneys from different groups with histopathological changes that also provided an essential evidence for the biochemical analysis. In control rats (Fig. 1), kidney sections showed normal glomeruli with an intact Bowman's capsule and convoluted tubules whereas STZ-treated group of rats (Fig. 2) showed glomerular congestion, inflammatory cells infiltration, necrosis and tubular dilations with nuclei bulging into the lumen. However, treatment with Cinnamon (Fig. 3) improved the histological architecture when compared to STZ-treated rats.

Effects on Body Weight of Rats: The control group (group - A) gained weight over the three weeks of experimental period, with the mean body weight increasing by $23.8 \mathrm{~g}$ after 3 weeks (Table 3 ). In contrast, the STZ-treated group (group - B) lost an average of $42.4 \mathrm{~g}$ after 3 weeks $(\mathrm{p}<0.05)$. Treatment with aqueous extract of Cinnamon (group-C) resulted in significant weight gain of $13.0 \mathrm{~g}$, rising towards the control group.

Effect of the Aqueous Extract of Cinnamon on Urea and Creatinine: The study indicates that serum urea and creatinine levels were significantly $(p<0.05)$ increased in streptozotocin-treated group (group B) when compared with the streptozotocin groups that was further treated with the extract (group C)and the control (group A) as depicted in Table 1above.

Renal Morphology:The renoprotecive activity of aqueous extract of Cinnamon was supported by histopathological studies of the kidney. It was observed that the aqueous extract of Cinnamon significantly protects rat kidneys from Diabetes-induced histopathological changes. This extract also normalized the derangements observed in serum creatinine and urea of diabetic rats. Both biochemical findings and histopathological evidence showed the renoprotective potential of aqueous extract of Cinnamon against Diabetes-induced renal dysfunction in rats.

Conclusion: It could be concluded that the crudeaqueous extract of Cinnamon was found to effectively improve the renal function and ameliorate lesions associated with nephrotoxicity in diabetic rats. This was shown by improved activities of serum creatinine and urea, and recovered renal cell architecture from injuries, by crudeaqueous extract of Cinnamon treatment in the diabetic rats. These results could further suggest that the probable use of aqueous extract of Cinnamon as a nutritional supplement could alleviatenephrotoxicity-induced detrimental effects in diabetic conditions and mightprotect renal cells fromfurther damages.

Acknowledgement: We wish to acknowledge all members of staff of the Department of Anatomy, University of Benin, Benin City for their support and encouragement throughout the period of this work.

\section{REFERENCES}

Abdul-Rahim, AI (2009). Effects of Cinnamon on blood glucose and lipids levels in diabetic patients (Type1). African Journal of Biochemical Research 3(5):181-184.

Begum, Q; Noori, S; Mahboob, T (2011).Antioxidant effect of sodium selenite on sthioacetamideinduced renal toxicity.Pakistan Journal of Biochemistry and Molecular Biology44 (1):2126.

Bolzan, AD; Bianchi, MS (2002).Genotoxicity of streptozotocin'.MutatRes 512 (2-3): Pg. 121-34.

Charles, C (1998). The scents of Eden: A Narrative of the Spice Trade. New York: Kodansha International. Pg. 202.

Etoh, T; Inoguchi, T; Kakimoto, M; Sonoda, N; Kobayashi, K; Kuroda, J; Sumimoto, H;Nawata, $\mathrm{H}$; (2003).Increased expression of NAD (P) $\mathrm{H}$ oxidase subunits, NOX4 and p22phox, in the kidney of streptozotocin-induced diabetic rats and its reversibity by interventive insulin treatment.Diabetologia,46(10):1428-1437.

Helping, C; Marilyn, MP; Richard, AA (2007). Cinnamon extract and polyphenols affect the expression of tristetraprolin, insulin receptor and glucose transporter 4 in mouse 3T3- L1 adipocytes. Archive of Biochemistry and Biophysis. 459:214-222.

Ho-Keun, K;Ji-Sun, H; Jae-Seon, S;Choong-Gu, L;Anupama, S; Jae-Ha,R; Won, KJ;Byoung, SK; Chang-Rok, IM; Sung, HL; Zee, YP; Sin-Hyeog IM (2010). Cinnamon extract reduces tumour cell death through inhibition of NFKB and API. BMC Cancer 10:392.

Inokuchi, J; Okabe, H;Yamanch, T;Nagamatu,A (1984). Inhibitors of angiotensin converting enzymes in crude drugs. Chemical and Pharmacological Bulletins 32:361-369. 
Jarvull-Taylor, KJ; Anderson, RA; Graves, DJ (2001).Functions as a mimetic for insulin in 3T3L1 adipocytes. Journal of America College of Nutrition 20:327-336.

Ozbek, E (2012). Induction of Oxidative Stress in Kidney.Int J Nephrol12:1-9.

Silva, FG (2004).Chemical-induced nephropathy: a review of the renal tubulointerstitial lesions in humans. ToxicolPathol,32 (2):71-84.
Shradha, B; Sisodia, SS (2011). Assessment of antidiabetic potential of Cinnamon tamala leaves extract in streptozotocin induced diabetic rats. Indian Journal of Pharmacology. 43(5): 582-5.

Wijesekera, RO (1978). Historical overview of the Cinnamon Industry. CRC Critical Review in food Science and Nutrition 10:1-30. 